\title{
Experimental evidence that quorum rules discourage turnout and promote election boycotts
}

Luís Aguiar-Conraria, ${ }^{1 *}$ Pedro C. Magalhães, ${ }^{2}$ Christoph A. Vanberg ${ }^{3}$

\begin{abstract}
Many democratic decision making institutions involve quorum rules. Such rules are commonly motivated by concerns about the "legitimacy" or "representativeness" of decisions reached when only a subset of eligible voters participates. A prominent example of this can be found in the context of direct democracy mechanisms, such as referenda and initiatives. We conduct a laboratory experiment to investigate the consequences of the two most common types of quorum rules: a participation quorum and an approval quorum. We find that both types of quora lead to lower participation rates, dramatically increasing the likelihood of full-fledged electoral boycotts on the part of those who endorse the Status Quo. This discouraging effect is significantly larger under a participation quorum than under an approval quorum.
\end{abstract}

Keywords: Election Design; Participation Quorum; Approval Quorum; Laboratory Experiment

JEL Codes: C91; D72; D02

\footnotetext{
1 NIPE and Economics Department, University of Minho, Campus de Gualtar, Braga 4710-057, Portugal.

* To whom correspondence should be addressed. E-mail: lfaguiar@eeg.uminho.pt.

2 Institute of Social Sciences, University of Lisbon, Av. Prof. Aníbal de Bettencourt, 9, Lisbon, Portugal.

${ }^{3}$ Alfred-Weber-Institut, University of Heidelberg, Bergheimer Str. 58, 69115 Heidelberg, Germany.
} 


\section{Introduction}

Many democratic decision making institutions involve quorum rules. The adoption of such rules is commonly motivated by concerns about the "legitimacy" or "representativeness" of decisions reached when only a subset of eligible voters participates. (LeDuc 2003: 172; Qvortrup 2005: 173). Instead of allowing measures to pass if they simply obtain the support of the majority of those who vote, participation quora require that the total number of votes exceeds a particular threshold. In other cases, the required threshold is applied to the number of votes cast in favor of the proposal (approval quora). In what concerns the regulation of referendums and initiatives, for example, quora have been adopted in many countries across the world (no less than 53, according to International IDEA's Direct Democracy dataset ${ }^{4}$ ), including Japan (Hizen and Shinmyo 2011), Colombia, Venezuela or Taiwan (International IDEA 2007), almost all of Germany for municipal and state referenda and initiatives (Kaufman, Büchi, and Braun 2007; Verhulst and Nijeboer 2007), and other seventeen European Union countries, either at the national (Aguiar-Conraria and Magalhães 2010a: 70) or the local levels (Schiller 2010: 28-30).

To be sure, when issues are placed on a ballot together with concurrent local, state or federal elections, as is common in the United States, the consequences of quora for voting behavior and their generalizability are more difficult to appreciate theoretically or empirically. However, even in countries such as the United States or Canada, special elections called specifically to hold a vote on a particular issue under quorum rules are certainly not unheard of, ${ }^{5}$ and, in general, special elections on single issue ballots are extremely common in most countries with direct democracy. ${ }^{6}$ What do we know about the consequences of quora in those cases?

Most of the theoretical and empirical research on this issue supports the same conclusion: participation quora decrease turnout. Theoretically, Côrte-Real and Pereira (2004) examine binary-choice voting rules and find that the addition of a turnout condition such as a participation quorum encourages abstention, allowing

\footnotetext{
${ }^{4}$ Available at: http://www.idea.int/uid/fieldview.cfm?field=327.

${ }^{5}$ Think, for example, of the April 2001 referendum on the Mississipi official flag or the British Columbia sales tax referendum of 2011, as well as the large number of local tax ballot measures voted across the US outside general election days.

${ }^{6}$ In fact, there are countries where holding national referenda and general elections simultaneously is explicitly precluded, as in the cases of Canada (under the Referendum Act) or Portugal (under the Constitution), for example.
} 
those who prefer the Status Quo to manipulate the outcome by failing to turn out. Similarly, Hizen and Shinmyo (2011) find that participation quora create incentives for strategic abstention when the participation quorum is anything other than negligibly low. From a different perspective, that of a group turnout model, Herrera and Mattozzi (2010) argue that participation quora distort the incentives for parties and interest groups to mobilize the electorate. Aguiar-Conraria and Magalhães investigate the matter both from the perspective of a decision theoretic model with exogenous pivotal probabilities (2010a) and in a pivotal voter model (2010b), in both cases suggesting that participation quora are likely to decrease turnout. Although empirical work remains scarce, case studies of particular countries and referenda have provided many illustrations of demobilizing effects of participation quora. Case studies on referenda held in Italy (Uleri 2002), the Weimar Republic (West 1985: 247; Suksi 1993: 95), Slovakia, and Columbia (International IDEA 2008: 182) have suggested that participation quora discourage turnout especially among opponents of the measure under consideration. The resulting differential turnout can lead to outcomes in which a large majority votes in favor of the measure, and yet it fails because the quorum is not reached. Finally, in a more systematic observational study, Aguiar-Conraria and Magalhães (2010a), using data for all referenda held in current European Union countries from 1970 until 2007, conclude that the existence of a participation quorum decreased turnout up to 14 percentage points.

There is a second main question about which results, taken together, are less conclusive: what are the different consequences of participation and approval quora? Herrera and Mattozzi (2010) argue that their analysis of participation quora carries over to approval quora, making them essentially equivalent. Anecdotal evidence does reveal several historical cases of very low levels of turnout on the part of those who prefer the Status Quo in referenda under approval quora, just like what happens with participation quora (Suksi 1993: 211; Svensson 1996: 38-40; Verhulst and Nijeboer 1007; 19-21). However, there are also indications that approval and participation quora may not be equivalent. On the basis of a pivotal voter model, Aguiar-Conraria and Magalhães (2010b) suggest that the two types of quora may promote different types of abstention, and describe situations where approval quora actually contribute to increase participation. In a different setup, where they distinguish between staying at home and abstaining, Laruelle and Valenciano (2011 and 2012) argue that the 
approval quorum is the one with the least distortionary effects, no matter what the majority rule is.

Given these contradictory findings about the equivalence of participation and approval quora, one might turn to the only systematic empirical study we know of, Aguiar-Conraria and Magalhães (2010a), which finds that, unlike participation quora, approval quora seem to have no effects on abstention. However, it is well known that the use of field data involves a number of drawbacks. For example, it can easily be argued that the type of quorum rule in use may be endogenous. Another disadvantage is that we can only observe realized outcomes, and do not know the distribution of "actual" preferences. Finally, the outcomes we observe are at the aggregate level, and (so far) we have little information about the separate effects of quora on Supporters and Opponents of proposals. Thus, it is possible that approval quora lead to lower turnout among opponents and higher turnout among supporters, leaving the aggregate level of participation unchanged. Similar concerns have motivated previous authors to conduct laboratory experiments to investigate factors affecting voter participation (Levine and Palfrey 2007; Duffy and Tavits 2008; Palfrey 2009).

Our approach in this study builds on prior experiments on voter participation. In particular, we introduce quorum rules into the pivotal voter model first developed by Palfrey and Rosenthal (1985). This model assumes that voting is instrumental, so that an individual's decision to vote depends on her beliefs about the likelihood of casting the decisive vote. The implications and comparative static predictions of the pivotal voter model have been supported by abundant experimental evidence (Levine and Palfrey 2007; Duffy and Tavits 2008; Palfrey 2009), while field evidence is consistent - at least in the margins - with the model's predictions about the effects of electorate size and election closeness (Blais 2000; Geys 2006). Our study is, to our knowledge, the first to test the effects of quorum rules under this framework in a controlled laboratory experiment. ${ }^{7}$

Our experimental design closely resembles that of Levine and Palfrey (2007), who test the effects of "closeness" and electorate size on turnout in an experimental pivotal voter game. The main difference between our setup and theirs is that we consider

\footnotetext{
${ }^{7}$ Previous papers by Schram and Sonnemans (1996), Morton and Tyran (2011), Battaglini et al. (2010), and Großer and Schram (2006 and 2010) have provided laboratory evidence on strategic abstention.
} 
three different quorum restrictions (no quorum, approval quorum, participation quorum). As in other experiments on the pivotal voter model, we measure an individual participant's propensity to vote under different conditions by eliciting her willingness to incur costs associated with voting.

Our results confirm prior evidence that quorum rules have important consequences for turnout. In addition, our experiment allows us to determine among which type of voters those consequences are stronger and what kind of quorum is more consequential. In particular, both approval and participation quora reduce participants' probability of voting. However, although the Opponents of the proposed measure are demobilized by both types of quora, this effect is significantly stronger under participation quora. Quora increase the probability that Opponents boycott the election, but do so more massively (increasing that probability by more than 40 percentage points) in the case of participation quora. Finally, we obtain the novel result that quora have different effects conditional on electors' preferences: while the evidence clearly shows that they strongly decrease the turnout rate of Opponents (preference for preserving the Status Quo), it also suggests they may increase the turnout rate of Supporters (preference for changing the Status Quo).

\section{The pivotal voter model with quorum requirements.}

We base our experiments on a variant of the pivotal voter model of Palfrey and Rosenthal (1985) put forward by Coate et al (2008). In this model, citizens are motivated to vote by the chance that they might swing the election. ${ }^{8} n$ electors ( $i=1, \ldots, n$, with $n=9$ ) decide, using majority rule, between two options labeled "Change" and "Status Quo". Prior to voting, each player is randomly assigned a preference for one of the two options. The ex-ante probability that an individual prefers Change is denoted $\mu$. This probability is known and common to all players, while the preference actually assigned to each player is private knowledge. ${ }^{9}$ We refer to the supporters of a proposal to change the Status Quo as "Supporters" and to those

\footnotetext{
${ }^{8}$ See Dhillon and Peralta (2002) and Fedderson (2004) for reviews of the strengths and weaknesses of the rational-choice approach, as well as of other approaches like group-based, expressed, or bounded rationality voting models.

${ }^{9}$ Unlike Levine and Palfrey (2007), we consider a game involving aggregate uncertainty, as in Borgers (2004) and Coate et al (2008). Although this implies an added degree of complexity, uncertainty about the actual percentages for and against the measure under consideration is a realistic feature of most voting situations.
} 
who prefer the Status Quo as "Opponents." After learning her own preference, each player decides to either vote or to abstain (as there is no incentive to vote for the opposing option, it is without loss of generality to restrict attention only to the participation decision). Each voter faces a cost of voting given by $c_{i}$, where $c_{i}$ is the realization of a uniformly distributed random variable, $c_{i} \sim U[0, c]$, with $c=100$. After votes are cast, the outcome is determined depending on the number of votes actually cast. In the absence of a quorum rule, the option receiving the larger number of votes is chosen. In the games with quorum rules, the Status Quo option wins unless the quorum is met and "Change" receives the majority of votes cast. ${ }^{10}$ If "Change" wins the election, Supporters obtain a benefit $b$. Otherwise, Opponents have a benefit of $x$. An individual voter's utility is equal to the realized benefit minus voting costs incurred.

Within the experiment, we will use groups of size $n=9$. As Levine and Palfrey (2007), we consider symmetric benefits: $b=x=100{ }^{11}$ Finally, we consider a participation quorum of 4 , and an approval quorum of $3 .{ }^{12}$ The probability of supporting change, $\mu$, was varied in order to implement two "close" and two "landslide" conditions. Specifically, we implement the following four conditions.

1. Landslide majority for Change:

$$
\mu=6 / 9=>E(\# \text { supporters, \#opponents) }=(6,3) \text {. }
$$

\footnotetext{
${ }^{10}$ Like Levine and Palfrey (2007), we assume that each option wins with $50 \%$ probability in case of a tie, provided that the quorum is met.

${ }^{11}$ These values were chosen because they imply, according to the no-quorum equilibrium predictions, relatively high turnout rates in the absence of a quorum. By choosing a high turnout equilibrium to start with, we are giving a chance that the quorum is not a binding constraint and that does not distort incentives. Had we started with low turnout rates in the no-quorum case, then quorum busting strategies would be very easy to implement and become the only equilibria (see the first scenario in Table 1). In such case, it would not be surprising to conclude that quora had deleterious effects.

${ }^{12}$ Given that quorum rules modify both the incentive structures and the set of results that correspond to Status Quo victory, we want to make the latter as similar as possible between quora in order to concentrate on the effects of the incentive structure. Choosing $P Q=4$ and $A Q=3$ accomplishes that. With 9 electors, there are 55 possible results. Of these, there are only two possible results that have different outcomes. If the Status Quo receives 0 votes and Change receives 3, then, with $A Q=3$, Change wins and with $P Q=4$ Status Quo wins. The other result is a 2-2. In that case, with $A Q=3$, Status Quo wins, while with $P Q=4$, Status Quo wins only with 50\% chances. Except for the trivial case of $A Q=1$ and $P Q=1$, in which the two quora are equivalent, the difference between the two Status Quo sets is minimized for these particular choices. For example, had we considered an $A Q=2$ and the Status Quo set would be a strict subset of the Status Quo region with $P Q=4$, meaning that the approval quorum threshold would undoubtedly be less restrictive than the participation quorum threshold. On the other hand, had we considered $\mathrm{AQ}=4$, and the opposite would happen, with the approval quorum Status Quo region being a strict superset of the Status Quo region in the participation quorum case.
} 
2. Close majority for Change:

$\mu=5 / 9=>$ E(\#supporters, \#opponents) $=(5,4)$.

3. Close majority for Status Quo:

$\mu=4 / 9=>$ E(\#supporters, \#opponents) $=(4,5)$.

4. Landslide majority for Status Quo:

$\mu=3 / 9=>E$ (\#supporters, \#opponents) $=(3,6)$.

In order to derive benchmark predictions, we will employ two different solution concepts. The first is Symmetric Bayes Nash Equilibrium (SBNE). As we will see, this concept will admit multiple equilibria when we consider games with either type of quorum. Equilibrium predictions for these conditions are derived in Appendix 1. In order to restrict the set of equilibria, we will also consider Quantal Response Equilibrium (QRE).

\subsection{Nash Equilibrium}

A strategy for elector $i$ is a function that specifies whether she votes or abstains for each possible realization of the idiosyncratic voting cost $c_{i}$. In any Bayes-Nash equilibrium, optimal strategies will follow a cutoff rule, according to which player $\mathrm{i}$ votes whenever his voting cost is smaller than some threshold $\gamma$, and otherwise abstains. We will look for Symmetric Bayes-Nash equilibria, which require that all members of a group follow the same strategy. Let $\gamma_{s}$ and $\gamma_{o}$ be the cutoff values for Supporters and Opponents, respectively. Our main interest will be to investigate how these cutoff values (and thus the probabilities of participation) are affected by the quorum rules under consideration.

Taking as given the strategies of the other players, let $\rho\left(v_{o}, v_{S}\right)^{13}$ be the probability that elector $i$ attaches to the event that, among the other electors, $v_{o}$ vote 'No' and $v_{s}$ vote 'Yes'. For each strategy pair, one can compute the probability of each result and, based on that, compute the probability of being pivotal and the expected benefit from voting. In equilibrium, the expected benefits must equal the strategy cutoff values.

Consider first the basic game in which there is no quorum rule. An elector is pivotal if her vote is necessary either to break or to reach the tie. For example, assume that an elector $i$ believes that without her vote the result will be 1 vote for the Status Quo and

\footnotetext{
${ }^{13}$ See Appendix 1 for a derivation of this probability function.
} 
2 for Change - (1,2). If individual $i$ is an Opponent and decides to vote, the probability that the Status Quo prevails increases by 0.5 percentage points, as her participation would guarantee a $(2,2)$ tie. Conversely, if she is a Supporter, her vote will change the result from $(1,2)$ to $(1,3)$. Hence, her vote would have zero impact on the final outcome.

Next, consider the participation quorum of 4. This rule introduces an additional way in which a voter may be pivotal. Namely, it could be that her vote is decisive in reaching the quorum, in addition to breaking a tie in case the quorum is met. This introduces and asymmetry between Supporters and Opponents. For a Supporter, the quorum introduces an additional incentive to participate, as there are now two ways in which her vote can tip the outcome her way. In contrast, it an Opponent may now have a reason not to participate, as she may be pivotal in an undesirable way: if her vote is decisive to meet the quorum and a majority votes in support of change, then her vote for the Status Quo actually causes "Change" to win.

As an example, consider again an elector who believes that without her vote the result will be 1 vote for the Status Quo and 2 votes for Change. Under a participation quorum of 4, a supporter's vote is pivotal, as her (additional) vote assures that the quorum is met, increasing the probability of "Change" by 1 . In contrast, for an Opponent, voting in this case will foster an undesirable outcome: instead of a victory for the Status Quo, obtained through the application of the quorum rule, an Opponent's participation will guarantee that the quorum is met, that the result is a tie, and, thus, that the probability of a Status Quo victory actually decreases by 0.5 . Under a participation quorum, Opponents may actually hurt themselves by voting.

Finally, consider the approval quorum of 3. As under a Participation Quorum, a Supporter may be pivotal either to make or to break a tie, or to reach the quorum. In contrast, an Opponent has no influence on the quorum in this case, so she can only be pivotal to make or break a tie, assuming that the quorum is reached. Thus, the AQ rule eliminates the possibility to be pivotal in an undesirable way, and thereby may increase the incentive for Opponents to participate.

Again, consider the example of an elector who believes that without her vote the result will be 1 vote for the Status Quo and 2 votes for Change. For an Opponent, the impact of voting is zero: with or without her vote, the quorum is not met and the 
Status Quo prevails anyway - in the previous example, however, with $\mathrm{PQ}=4$, the impact of voting was not zero, it was negative. For a supporter of Change, the 'Yes' is decisive to reach the approval quorum of 3 , by moving the result from $(1,2)$ to $(1,3)$, creating incentives to vote that would not be there in the absence of a quorum rule.

Assuming an interior solution, the expected benefits of voting must equal the cost of voting at the equilibrium cutoff values. For each quorum rule, this gives us two equations in two unknowns $\left(\gamma_{s}, \gamma_{o}\right)$ :

$\left\{\begin{array}{l}{\left[\sum_{v=0}^{4} \frac{\rho(v, v)}{2}+\sum_{v=0}^{3} \frac{\rho(v+1, v)}{2}\right] b=\gamma_{s} \wedge\left[\sum_{v=0}^{4} \frac{\rho(v, v)}{2}+\sum_{v=0}^{3} \frac{\rho(v, v+1)}{2}\right] x=\gamma_{o}, \text { if } N Q} \\ {\left[\sum_{v=2}^{4} \frac{\rho(v, v)}{2}+\sum_{v=1}^{3} \frac{\rho(v+1, v)}{2}+\rho(1,2)+\rho(0,3)\right] b=\gamma_{S} \wedge\left[\sum_{v=2}^{4} \frac{\rho(v, v)}{2}+\sum_{v=2}^{3} \frac{\rho(v+1, v)}{2}-\frac{\rho(1,2)}{2}-\rho(0,3)\right] x=\gamma_{o^{\prime}} \text { if } P Q=4} \\ {\left[\sum_{v=3}^{4} \frac{\rho(v, v)}{2}+\sum_{v=2}^{3} \frac{\rho(v+1, v)}{2}+\sum_{v=0}^{2} \rho(v, 2)\right] b=\gamma_{S} \wedge\left[\sum_{v=3}^{4} \frac{\rho(v, v)}{2}+\sum_{v=2}^{3} \frac{\rho(v, v+1)}{2}\right] x=\gamma_{o^{\prime}} \text { if } A Q=3}\end{array}\right.$

We find the equilibria numerically. Without quorum, our model is the same as Coate et al. (2008). As Coate et al. (2008) explain there is always a pair $\left(\gamma_{s}, \gamma_{o}\right)$ that satisfies the system of equations. In the presence of a quorum, it is also obvious that $\left(\gamma_{s}, \gamma_{0}\right)=$ $(0,0)$ always satisfies those equations, as the probability of being pivotal is then zero. However, there are no general uniqueness results. Given that our problem is only twodimensional and bounded, we perform a detailed grid search to look for several equilibria.

In the absence of a quorum rule, the equilibrium turns out to be unique. In the presence of quora, multiple equilibria arise. As mentioned, there will always be a "no show" equilibrium. A second type of equilibrium involves zero turnout among Opponents, but positive turnout among Supporters. In such equilibria, Supporters have an incentive to vote in order to meet the quorum, and an individual Opponent cannot change the outcome to her advantage. Finally, equilibria with positive turnout for both Supporters and Opponents are possible. Generally, these equilibria are either similar to the no quorum equilibrium or involve some lower participation rates among Opponents and higher among Supporters.

The willingness to pay associated with each of the Nash equilibria under each of the above scenarios are presented in Table 1. For example, if the willingness to pay is 60 , then if the voting cost is not above that threshold, the elector will vote. As the voting cost is uniformly distributed between 0 and 100, these numbers can be interpreted as individual probabilities of casting a vote. The mean of the individual probabilities of 
casting a vote captures the expected turnout. E.g., if the average willingness to pay is 60 , then expected turnout is simply $60 \%$. That means that, in our context, policies that reduce the willingness to pay will also lead to lower expected turnout.

Despite the multiplicity of equilibria, a number of interesting patterns are discernible from Table 1. Most importantly, both types of quora are associated with lower overall levels of turnout than the no quorum condition. Both types of quora unambiguously reduce equilibrium turnout among Opponents, in many equilibria to zero. The effect of quora on Supporters is ambiguous. Therefore, a central prediction emerges: both types of quora should reduce overall participation rates among Opponents.

Table 1: Probability of voting for different quorum rules, odds and profiles (Nash Equilibria)

\begin{tabular}{|c|c|c|c|c|c|c|c|c|c|}
\hline \multicolumn{2}{|c|}{ Treatment } & \multicolumn{2}{|c|}{$\begin{array}{c}\text { Clear } \\
\text { majority } \\
\text { for Change: } \\
\mu=6 / 9\end{array}$} & \multicolumn{2}{|c|}{$\begin{array}{c}\text { Borderline } \\
\text { majority } \\
\text { for Change: } \\
\mu=5 / 9\end{array}$} & \multicolumn{2}{|c|}{$\begin{array}{c}\text { Borderline } \\
\text { majority } \\
\text { for Status } \\
\text { Quo: } \\
\mu=4 / 9\end{array}$} & \multicolumn{2}{|c|}{$\begin{array}{c}\text { Clear } \\
\text { majority } \\
\text { for Status } \\
\text { Quo: } \\
\mu=3 / 9\end{array}$} \\
\hline No quorum & eq1 & 88 & 70 & 88 & 82 & 82 & 88 & 70 & 88 \\
\hline \multirow{5}{*}{$\begin{array}{l}\text { Participation } \\
\text { Quorum }\end{array}$} & eq1 & - & - & 87 & 82 & 82 & 89 & 69 & 92 \\
\hline & eq2 & - & - & 47 & 83 & 35 & 98 & 34 & 72 \\
\hline & eq3 & $\mathbf{0}$ & 87 & $\mathbf{0}$ & 100 & 0 & 100 & 0 & 100 \\
\hline & eq 4 & $\mathbf{0}$ & 12 & $\mathbf{0}$ & 17 & 0 & 25 & $\mathbf{0}$ & 41 \\
\hline & eq5 & $\mathbf{0}$ & $\mathbf{0}$ & $\mathbf{0}$ & $\mathbf{0}$ & $\mathbf{0}$ & $\mathbf{0}$ & 0 & $\mathbf{0}$ \\
\hline \multirow{5}{*}{$\begin{array}{l}\text { Approval } \\
\text { Quorum }\end{array}$} & eq1 & - & - & 85 & 83 & 81 & 90 & 68 & 97 \\
\hline & eq2 & - & - & 30 & 84 & 17 & 99 & 16 & 100 \\
\hline & eq3 & 0 & 73 & 0 & 84 & 0 & 99 & 0 & 100 \\
\hline & eq4 & $\mathbf{0}$ & 1 & $\mathbf{0}$ & 2 & $\mathbf{0}$ & 3 & 0 & 6 \\
\hline & eq5 & $\mathbf{0}$ & $\mathbf{0}$ & $\mathbf{0}$ & $\mathbf{0}$ & 0 & $\mathbf{0}$ & 0 & $\mathbf{0}$ \\
\hline
\end{tabular}

$\mathrm{n}=9, \mathrm{PQ}=4, \mathrm{AQ}=3$

Legend:

Opponents

Supporters

Prediction 1: Under both $P Q$ and $A Q$, participation rates among Opponents are lower than in the absence of a quorum rule (and possibly zero).

However, there are two questions for which it is difficult to derive clear cut predictions:

1. Which type of quorum produces the largest demobilizing effect among Opponents, if such a difference is to be found at all? 
2. What is the net effect among Supporters?

Regarding question 1, the theoretical analysis does not provide unambiguous predictions on these effects, as we do not know the likelihood with which each of the possible equilibria might arise in reality. However, the results in Table 1 do suggest the testable proposition that the turnout rate may actually be higher among Supporters in the presence of quora.

\subsection{Quantal Response Equilibrium}

As we have seen, the set of SBNE is quite large under the quorum rules. One possibility to narrow down the set of equilibria is to look at the set of Quantal Response Equilibria (QRE). QRE is derived by introducing noise into player strategies. Rather than always choosing a best response, players are assumed to choose better options with greater probability. In our context, a voter who is indifferent between voting or not will vote with probability $50 \%$. As her cost of voting increases or decreases, this probability will decrease or increase continuously. We will rely on the logit quantal response equilibrium model, meaning that for a voting cost $c_{i}$, the probability of voting is given by $\frac{1}{1+\exp \left(\lambda\left(c_{i}-\pi_{i} B\right)\right)}$, where $\pi_{i}$ is the probability of being pivotal, $B$ is the payoff of winning the election, and $\lambda$ is the socalled "response parameter". The larger is $\lambda$, the more "responsive" the probability of voting will be to the expected net benefit of voting. As $\lambda \rightarrow \infty$, QRE approaches the Nash equilibrium and as $\lambda \rightarrow 0$, each voter will simply vote with $50 \%$ probability, irrespective of her voting cost and the probability of being pivotal. Integrating over all possible costs, one derives the ex-ante probability of voting. To find the equilibrium, we solve a system of equations analogous to system of equations (1).

To numerically find the equilibria one needs to calibrate a value for $\lambda$. Levine and Palfrey (2007) estimate $\lambda$ with the data of their experiment. Mapping the payoff parameters of their model to ours, that corresponds to a $\lambda$ about $0.04 .{ }^{14}$ In Table 2, we have the expected turnout rates for each of the scenarios predicted by QRE with $\lambda=0.04$.

\footnotetext{
${ }^{14}$ It is difficult to estimate $\lambda$ in our treatments with quora, because of the existence of multiple equilibria. From the data, it is difficult to distinguish a low $\lambda$ from players playing different equilibria. Using data from our No Quorum treatments our estimates suggest that $\lambda$ is between 0.03 and 0.035 , which is very similar to the estimates of Levine and Palfrey.
} 
Table 2: Probability of voting for different quorum rules, odds and profiles (QRE, $\lambda=0.04)$

\begin{tabular}{|c|c|c|c|c|c|c|c|c|c|}
\hline \multicolumn{2}{|c|}{ Treatment } & \multicolumn{2}{|c|}{$\begin{array}{c}\text { Clear } \\
\text { majority } \\
\text { for Change: } \\
\mu=6 / 9\end{array}$} & \multicolumn{2}{|c|}{$\begin{array}{c}\text { Borderline } \\
\text { majority } \\
\text { for Change: } \\
\mu=5 / 9\end{array}$} & \multicolumn{2}{|c|}{$\begin{array}{c}\text { Borderline } \\
\text { majority } \\
\text { for Status } \\
\text { Quo: } \\
\mu=4 / 9\end{array}$} & \multicolumn{2}{|c|}{$\begin{array}{c}\text { Clear } \\
\text { majority } \\
\text { for Status } \\
\text { Quo: } \\
\mu=3 / 9\end{array}$} \\
\hline $\begin{array}{l}\text { No } \\
\text { Quorum }\end{array}$ & eq1 & 78 & 66 & 79 & 75 & 75 & 79 & 66 & 78 \\
\hline \multirow{3}{*}{$\begin{array}{l}\text { Participation } \\
\text { Quorum }\end{array}$} & eq1 & - & - & 75 & 77 & 73 & 81 & 62 & 85 \\
\hline & eq2 & - & - & 48 & 79 & 36 & 91 & 34 & 96 \\
\hline & eq3 & 0 & 83 & 0 & 92 & $\mathbf{0}$ & 98 & $\mathbf{0}$ & 98 \\
\hline $\begin{array}{l}\text { Approval } \\
\text { Quorum }\end{array}$ & eq1 & 24 & 71 & 72 & 79 & 71 & 83 & 59 & 89 \\
\hline
\end{tabular}

$\mathrm{n}=9, \mathrm{PQ}=4, \mathrm{AQ}=3$

\section{Legend: Opponents Supporters}

The set of equilibria changes radically under QRE (with $\lambda=0.04$ ) relative to SBNE. Two patterns are worth pointing out. First, under the approval quorum, equilibria with very low turnout among Opponents almost disappeared, while under participation quorum, almost zero turnout among Opponents is always one possible equilibrium. This suggests that this type of behavior is much more likely to occur under a participation quorum than under an approval quorum. Second, all equilibria predict that turnout increases among Supporters in the presence of a quorum.

Based on these results, QRE as a solution concept supports the hypothesis that (a) the demobilization effect among Opponents should be larger under a participation quorum than under an approval quorum, and (b) an increase in turnout among Supporters is to be expected in the presence of a quorum.

Prediction 2: Participation among Opponents is lower under $P Q$ than under $A Q$, and full-scale "boycott" is more likely to occur under $P Q$.

Prediction 3: Under both $P Q$ and AQ, participation rates among Supporters are higher than in the absence of a quorum rule. 


\section{Experimental design}

The experiment follows a $3 \times 4$ design to investigate outcomes under the three quorum conditions (no quorum, participation quorum, approval quorum) within each of the 4 preference scenarios (clear / borderline majority for / against Change). More specifically, we conducted two different between subject (or between group) treatments: a Participation Quorum of 4, and an Approval Quorum of 3. Within each of these treatments, we conducted two within subject (or within group) treatments, comparing one of the quorum rules with a no quorum baseline condition. Finally, within each of these 3 conditions (i.e. within each group), we varied the probability that an individual voter is a Supporter of "Change" to implement the four preference scenarios.

Table 3. Within- and between subject treatments

\begin{tabular}{|c|c|c|}
\hline \multirow{2}{*}{$\begin{array}{c}\text { Within } \\
\text { group/subject }\end{array}$} & Approval Quorum & Participation Quorum \\
comparisons & (4 scenarios) & (4 scenarios) \\
\cline { 2 - 3 } & \multicolumn{2}{|c|}{ No Quorum } \\
& \multicolumn{2}{|c|}{ (4 scenarios) } \\
\hline
\end{tabular}

The experiment was conducted at the experimental laboratory of the Alfred Weber Institute of Economics at the University of Heidelberg, Germany. It involved 144 subjects, all of whom were students of the University of Heidelberg. ${ }^{15}$ We conducted a total of 8 sessions (4 PQ and 4 AQ) involving 18 subjects per session. Within each session, subjects were randomly assigned to one of two groups of size 9. These groups remained fixed throughout the experiment, which lasted for 48 rounds. ${ }^{16}$ Payoffs in the game were expressed as "points," with each point corresponding to 5 cents.

\footnotetext{
${ }^{15}$ Subjects were recruited using the online recruitment system ORSEE (Greiner 2004). The experiment was programmed using the software z-Tree (Fischbacher 2007). Students came from various disciplines (approximately $45 \%$ economics, $20 \%$ other social sciences, $10 \%$ natural sciences, $25 \%$ humanities). $45 \%$ of our subjects were female.

${ }^{16}$ Subjects were not explicitly informed that they would repeatedly interact with the same set of participants. It is important to note that despite this "fixed matching" scheme, subjects were randomly assigned to the two "teams" at the beginning of each round.
} 
At the start of each round, subjects were randomly assigned to one of two teams, labeled "A" and "B." Although neutrally labeled, one of these options represented the "Status Quo" while the other represented "Change." Next, subjects were informed about the existence of the quorum rule (if any), and asked to state a willingness to pay (WTP), between 0 and 100 points $(€ 5)$, to cast a vote in favor of their team. Each subject was then randomly assigned a 'voting cost' (VC) uniformly distributed between 0 and 100 points. If the $\mathrm{VC}$ was smaller than or equal to the $\mathrm{WTP}$, the subject was said to cast a vote, and the randomly determined VC was subtracted from her earnings in the game. If the VC exceeded the WTP, the subject was said to abstain and no cost was subtracted. ${ }^{17}$ After all subjects submitted their decisions, the votes actually cast were counted and the winning option determined as per the quorum rule in effect. Subjects belonging to the winning team earned 600 points $(€ 30)$. At the end of the experiment, participants were paid the average of 10 randomly chosen rounds, in addition to a $€ 5$ show up fee. ${ }^{18}$ On average, each participant received $€ 21$.

Within an experimental session, the probability of favoring Change varied over the course of 48 independent elections (experimental rounds), implementing the four different within-group treatment conditions: a landslide majority for the Status Quo (6/3); a close majority for the Status Quo (5/4); a close majority for Change (4/5); and a landslide majority for Change (3/6). In addition, the quorum rule varied, from round to round, between no quorum (NQ) and either an approval quorum of 3 (AQ) or a participation quorum of 4 (PQ). ${ }^{19}$

\footnotetext{
${ }^{17}$ A potential drawback of this (strategy) method is that it forces participants to use a cutoff strategy, as predicted by theory. If our goal was to test this aspect of the theory, this would be an inappropriate design choice. However, our aim is to investigate the effects of the quorum rules on participation, and not to test the use of cutoff strategies. Still it is important to note that Levine and Palfrey do find that "to a reasonable approximation individuals followed consistent cutpoint rules" (2007: 152). Therefore we are confident that forcing subjects to use cutoff strategies did not restrict their behavior significantly. See Brandts and Charness (2011) for a more general discussion of the strategy method and how it compares to the direct response method.

${ }^{18}$ This method of payment was chosen as a good compromise between avoiding paying all rounds (introducing wealth effects) and paying only one round (introducing additional risk). See Morton and Wiliams (2010: 399) for a discussion of this methodological choice.

${ }^{19}$ I all sessions, the probability of favoring change cycled deterministically as follows: 3/9, 6/9, 4/9, $5 / 9$. The sequence of no quorum / quorum conditions was counterbalanced. In half of the sessions, the sequence was: 8 rounds with quorum, 4 without, 8 with, etc. In the other sessions, we began with 4 rounds no quorum, 8 with, etc. (We conduct twice as many rounds with quora because in that case the game is not symmetric and so we acquire fewer observations when distinguishing between supporters and opponents.) All random team assignments were drawn once prior to the first session and kept constant in all sessions. I.e. the realized numbers of Supporters and Opponents were the same in all treatments.
} 
As these conditions varied within the sessions, we can conduct within-subject and within-group comparisons between NQ and either AQ or PQ, as well as betweensubject and between-group comparisons between AQ and PQ. Note that, in the case of no quorum, the game is perfectly symmetric and, therefore, there is no distinction between the "Status Quo" and "Change." Thus, overall, we have $2+4 \times 2=10$ treatment conditions. Experiment instructions are described in detail in the Appendix 2.

\section{Descriptive statistics and preliminary tests}

In this section, we display some descriptive statistics, such as means and standard deviations (conditional on the quorum classifications and minority/majority classifications). We also show some non-parametric tests that help us establish a first set of results.

As indicated above, we conducted 8 sessions, involving 16 groups of 9 participants. Since the composition of groups remained fixed throughout each session, we have 16 statistically independent observations. When conducting non-parametric tests, we therefore use the group as our basic unit of observation, and concentrate on the grouplevel averages of the variables of interest.

As we explained before, eight groups were subjected to the "No quorum" and "Approval quorum" treatments and another eight groups were subjected to the "No quorum" and "Participation quorum" treatments.

All comparisons between either quorum rule and the "no quorum" benchmark will use data from only the 8 groups who were exposed to the particular quorum type, e.g., we do not include the "no quorum" data from the 8 PQ sessions when we compare AQ to NQ. Thus, these comparisons will be based on 8 independent pairs of observations, and we will use Wilcoxon signed-rank tests to assess the significance of any differences observed.

To compare the two different quorum types, we can use all 16 observations, 8 independent observations per condition. Significance will be based on the MannWhitney $\mathrm{U}$ test for independent samples (also known as the Wilcoxon rank sum test). 
We divide the presentation in 4 tables, Tables 4 a to $4 \mathrm{~d}$, with one table for each odds treatment $(\mu=3 / 9,4 / 9,5 / 9,6 / 9)$. In each table, we have the average willingness to pay and the standard deviation that corresponds to each treatment. In the third column, we present the p-value of the Wilcoxon signed-rank test for the null that means are equal under quorum and no quorum. Finally, in the last column, we show the p-value associated with the Mann-Whitney $U$ test, for the null that the means are the same for both quorum types.

When we compare any quorum treatment with no quorum, we see that the Willingness To Pay (WTP) - i.e. the probability of voting, as voting costs are drawn from a $(0,100)$ uniform distribution - always decreases for Opponents, and almost always in a statistically significant way. This supports Prediction 1 formulated above.

Result 1: Among Opponents, the average WTP to cast a vote is significantly lower under both $A Q$ and $P Q$ than in the absence of a quorum. Thus, expected rates of participation among Opponents are significantly lower in the presence of either quorum rule.

For Supporters, the results are less clear-cut. Consistent with Prediction 3, turnout among Supporters increases in almost all scenarios in the presence of a quorum. However, these differences are not always statistically significant. Part of the explanation for this lack of statistical significance may be attributed to the low power of the statistical effects that can be performed when one uses session averages as the unit of observation (see Frechétte 2012). 
Table 4: Descriptive statistics and preliminary tests

\begin{tabular}{|c|c|c|c|c|c|}
\hline & & $\begin{array}{l}\text { Mean } \\
\text { WTP }\end{array}$ & St dev & $\begin{array}{c}\text { AQ / PQ } \\
\text { vs. } \\
\text { NQ } \\
\text { (p-val) }\end{array}$ & $\begin{array}{c}\text { PQ vs. AQ } \\
\text { (p-val) }\end{array}$ \\
\hline \multirow{3}{*}{ Opponent } & $\mathrm{NQ}_{\mathrm{aq}} ; \mathrm{NQ}_{\mathrm{pq}}$ & $25.2 ; 25.3$ & $8.4 ; 4.9$ & & \\
\hline & $\mathrm{AQ}$ & 16.2 & 9.6 & 0.109 & \multirow{2}{*}{0.161} \\
\hline & PQ & 8.8 & 6.7 & 0.008 & \\
\hline \multirow{3}{*}{ Supporter } & $\mathrm{NQ}_{\mathrm{aq}}, \mathrm{NQ}_{\mathrm{pq}}$ & $57.0 ; 64.4$ & $6.7 ; 8.7$ & & \\
\hline & $\mathrm{AQ}$ & 67.3 & 7.8 & 0.015 & \multirow{2}{*}{0.721} \\
\hline & PQ & 68.5 & 7.3 & 0.195 & \\
\hline
\end{tabular}

Table 4b: Borderline majority for Change: $\quad \mu=5 / 9$

\begin{tabular}{|c|c|c|c|c|c|}
\hline & & $\begin{array}{l}\text { Mean } \\
\text { WTP }\end{array}$ & St dev & $\begin{array}{c}\text { AQ / PQ } \\
\text { vs. } \\
\text { NQ } \\
\text { (p-val) }\end{array}$ & $\begin{array}{c}\text { PQ vs. AQ } \\
\text { (p-val) }\end{array}$ \\
\hline \multirow{3}{*}{ Opponent } & $\mathrm{NQ}_{\mathrm{aq}} ; \mathrm{NQ}_{\mathrm{pq}}$ & $46.4 ; 48.7$ & $8.6 ; 13.2$ & & \\
\hline & $\mathrm{AQ}$ & 33.3 & 15.0 & 0.039 & \multirow{2}{*}{0.083} \\
\hline & $\mathrm{PQ}$ & 18.9 & 13.8 & 0.008 & \\
\hline \multirow{3}{*}{ Supporter } & $\mathrm{NQ}_{\mathrm{aq}} ; \mathrm{NQ}_{\mathrm{pq}}$ & $59.4 ; 62.9$ & $8.4 ; 14.0$ & & \\
\hline & $\mathrm{AQ}$ & 61.1 & 7.2 & 0.547 & \multirow{2}{*}{0.382} \\
\hline & PQ & 65.1 & 12.6 & 0.742 & \\
\hline
\end{tabular}

\begin{tabular}{|c|c|c|c|c|c|}
\hline & & $\begin{array}{l}\text { Mean } \\
\text { WTP }\end{array}$ & St dev & $\begin{array}{c}\text { AQ / PQ } \\
\text { vs. } \\
\text { NQ } \\
\text { (p-val) }\end{array}$ & $\begin{array}{c}\text { PQ vs. AQ } \\
\text { (p-val) }\end{array}$ \\
\hline \multirow{3}{*}{ Opponent } & $\mathrm{NQ}_{\mathrm{aq}}, \mathrm{NQ}_{\mathrm{pq}}$ & $59.4 ; 62.9$ & $8.4 ; 14.0$ & & \\
\hline & $\mathrm{AQ}$ & 39.3 & 16.0 & 0.008 & \multirow{2}{*}{0.279} \\
\hline & PQ & 27.1 & 22.7 & 0.008 & \\
\hline \multirow{3}{*}{ Supporter } & $\mathrm{NQ}_{\mathrm{aq}}, \mathrm{NQ}_{\mathrm{pq}}$ & $46.4 ; 48.7$ & $8.6 ; 13.2$ & & \\
\hline & $\mathrm{AQ}$ & 43.6 & 8.2 & 0.383 & \multirow{2}{*}{0.015} \\
\hline & $\mathrm{PQ}$ & 55.7 & 10.2 & 0.109 & \\
\hline
\end{tabular}

\begin{tabular}{|c|c|c|c|c|c|}
\hline & & $\begin{array}{l}\text { Mean } \\
\text { WTP }\end{array}$ & St dev & $\begin{array}{c}\text { AQ / PQ } \\
\text { vs. } \\
\text { NQ } \\
\text { (p-val) }\end{array}$ & $\begin{array}{c}\text { PQ vs. AQ } \\
(p-v a l)\end{array}$ \\
\hline \multirow{3}{*}{ Opponent } & $\mathrm{NQ}_{\mathrm{aq}} ; \mathrm{NQ}_{\mathrm{pq}}$ & $57.0 ; 64.4$ & $6.7 ; 8.7$ & & \\
\hline & $\mathrm{AQ}$ & 36.9 & 13.8 & 0.008 & \multirow{2}{*}{0.161} \\
\hline & $\mathrm{PQ}$ & 25.9 & 19.5 & 0.008 & \\
\hline \multirow{3}{*}{ Supporter } & $\mathrm{NQ}_{\mathrm{aq}} ; \mathrm{NQ}_{\mathrm{pq}}$ & $25.2,25.3$ & $8.4 ; 4.9$ & & \\
\hline & $\mathrm{AQ}$ & 31.1 & 10.8 & 0.055 & \multirow{2}{*}{0.083} \\
\hline & $\mathrm{PQ}$ & 42.2 & 12.0 & 0.008 & \\
\hline
\end{tabular}

Note: The second and third columns present the mean and standard deviation of group means.

$\mathrm{NQ}_{\mathrm{aq}} / \mathrm{NQ}_{\mathrm{pq}}$ refers to the No Quorum treatment in the groups that also had the Approval Quorum/Participation Quorum treatment. 
Of the eight possible comparisons between PQ and AQ, only three yield statistically significant differences. Thus, the nonparametric analysis based on session averages does not yield support for Prediction 2. None the less, we can see that average turnout among Opponents is lower under PQ than AQ in all four scenarios. As we will see in section 5.1, when we use all the available information and control for individual and group effects, these differences are strongly significant.

\section{Regression results}

\subsection{Turnout rates}

We estimate a regression model where WTP ("willingness to pay") is the dependent variable and the explanatory variables are dummies for the combinations between the different quorum treatments and the values of $\mu$ and, for the quorum conditions, whether subjects are Opponents or Supporters. In contrast to the non-parametric analysis in the previous section, this approach allows us to use all the information on all individual actions of the experimental subjects.

We control for individual random effects and for the round number — which is like a time trend with each period corresponding to a round in the game. ${ }^{20}$ The time trend was statistically significant up to a third order polynomial. It is an increasing function up to round 23, at which point it stabilizes. Comparing round 23 to round 1, we can observe an increase in turnout around 10 percentage points.

Figure 1 displays the results graphically, and Table 5 provides more detailed information on the individual coefficients. The constant corresponds to the treatment of Clear Minority under No Quorum. In the second to the last column, we include the result of a Wald test for the null that the quorum treatment has no effect. In the last column we perform the same test for the difference between the participation quorum and the approval quorum.

Figure 1.a shows the estimated WTP — i.e. the probability of voting, as voting costs are drawn from a $(0,100)$ uniform distribution — both for the no quorum situation and

\footnotetext{
${ }^{20}$ Considering a model with individual fixed effects yields almost identical results, showing that any individual and group effects are very well controlled for, with the random effects model. Also, given the bounded nature of the dependent variable, one could have on model of fractional response variables a la Papke and Wooldridge (2008). The results were nearly identical, so there is no obvious advantage in using this more complicated framework.
} 
for Supporters and Opponents under the participation quorum, depending on the (increasing) probability that each other member of the electorate are in the same team, from a clear majority against (3/6) to a clear majority in support (6/3). ${ }^{21}$ Figure 1.b shows the same, but this time replacing the participation quorum with the approval quorum condition. Finally, Figure 1.c focuses on the effects of quora for Opponents in comparison with the No quorum situation. To compute the voting probability, we considered Round $=25$ (about the mean value).

Overall, as Figures 1.a and 1.b show, under all quorum conditions, WTP was lowest when subjects expected to be a clear minority, and larger when the election was expected to be close.

We can also see that the quorum rules affect the propensity to vote in different ways, depending on whether subjects are Opponents or Supporters.

For Opponents, the negative marginal effects of quora, seen in Figure 1.c, were statistically significant and large. ${ }^{22}$ It is also clear that the Participation Quorum has a stronger demobilization effect than the Approval Quorum. Moreover, the last column of Table 5, where we test the null that there is no difference between both quora, tells us that the stronger demobilizing effect of the Participation Quorum is always statistically significant at least at 5\%. This yields support for Prediction 2

Result 2: $P Q$ causes participation rates among Opponents to drop significantly more strongly than does $A Q$.

In contrast, for Supporters, there is evidence of an increase in the turnout rates in comparison with the No quorum situation.

Result 3: Both AQ and PQ have either no effect or a positive effect on turnout among Supporters.

In sum, quora affect Opponents and Supporters in different ways: there is strong and unambiguous evidence that they decrease the turnout of those who oppose the measure changing the Status Quo, and some evidence that it increases Supporters'

\footnotetext{
${ }^{21}$ Take, for example, the 3/6 case. This means that for Supporters there is a clear majority against Change. For Opponents, there is a clear majority for Change.

22 Even in the only case in which the $95 \%$ confidence interval includes zero, Table 4 , in the second to the last column, tells us that the effect is still statistically significant at $10 \%$.
} 
turnout. Furthermore, as Figures 1.a and 1.b clearly suggest, the increased WTP for Supporters only partially offsets the decrease among Opponents. The result is that quora decrease overall turnout.

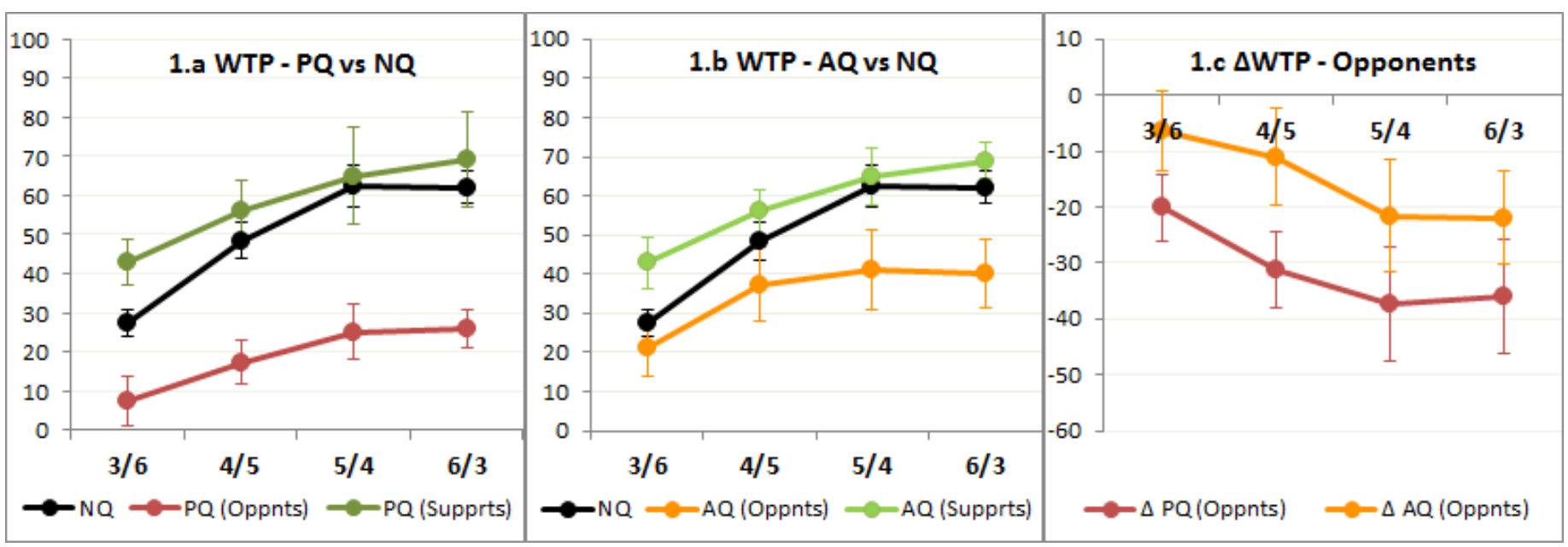

Figure 1: Experimental results depending on the (increasing) probability that each other member of the electorate belongs to their team, from a clear majority against (3/6) to a clear majority in support (6/3). (a) The 'willingness to pay' (WTP) without quorum (NQ) and for Opponents and Supporters under the participation quorum (PQ). (b) WTP without quorum (NQ) and for Opponents and Supporters under the approval quorum (AQ). (c) The effects of quora for Opponents in comparison with the no quorum situation. Error bars denote $95 \%$ confidence intervals.

The results in Table 5, more than just confirming the information of Figure 1, also clarify the several situations where the confidence intervals of Figure 1 overlap. For example, the increase of turnout among Supporters is, with one exception, always significant, when one compares the participation quorum with no quorum. In the case of an approval quorum, this effect is statistically significant only when Supporters are in clear majority.

If quora affect turnout, which type of quorum has the largest effects? In Table 5, last column, we test the difference between the participation and approval quora on turnout. For Supporters, differences are statistically significant only when they expect to be in minority. However, for Opponents, participation is always significantly less in the case of the participation quorum. The same was visible in Figure 1.c, which shows demobilization effects of the participation quorum that are always larger than under approval quora and under all values of $\mu$. 
Table 5: Random effects model of the Willingness To Pay to vote

\begin{tabular}{|c|c|c|c|c|}
\hline & Coefficient & Std. Error & $\begin{array}{l}\text { Wald test } \\
\mathrm{Q}=\mathrm{NQ}\end{array}$ & $\begin{array}{l}\text { Wald test } \\
A Q=N Q\end{array}$ \\
\hline 1- Constant & 17.3 & 2.3 & & \\
\hline 2- AQ, Opponent, clear minority & -6.5 & 3.7 & $*$ & \multirow{2}{*}{$* * *$} \\
\hline 3- PQ, Opponent, clear minority & -20.0 & 3.0 & $* * *$ & \\
\hline 4- AQ, Supporter, clear minority & 6.1 & 3.8 & ns & \multirow{2}{*}{$*$} \\
\hline 5- PQ, Supporter, clear minority & 15.5 & 3.2 & $* * *$ & \\
\hline 6- NQ, borderline minority & 21.0 & 2.3 & & \\
\hline 7- AQ, Opponent, borderline minority & 9.9 & 4.9 & $* *$ & \multirow{2}{*}{$* * *$} \\
\hline 8- PQ, Opponent, borderline minority & -10.2 & 4.3 & $* * *$ & \\
\hline 9- AQ, Supporter, borderline minority & 20.0 & 3.1 & ns & \multirow{2}{*}{$* *$} \\
\hline 10- PQ, Supporter, borderline minority & 28.5 & 3.1 & $* * *$ & \\
\hline $11-\mathrm{NQ}$, borderline majority & 35.1 & 3.3 & & \\
\hline 12- AQ, Opponent, borderline majority & 13.5 & 5.8 & $* * *$ & \multirow{2}{*}{$* *$} \\
\hline 13- PQ, Opponent, borderline majority & -2.3 & 6.6 & $* * *$ & \\
\hline 14- AQ, Supporter, borderline majority & 36.4 & 3.2 & ns & \multirow{2}{*}{ ns } \\
\hline 15- PQ, Supporter, borderline majority & 37.5 & 4.0 & ns & \\
\hline 16- NQ, clear majority & 34.6 & 2.9 & & \\
\hline 17- AQ, Opponent, clear majority & 12.7 & 5.4 & $* * *$ & \multirow{2}{*}{$* *$} \\
\hline 18- PQ, Opponent, clear majority & -1.5 & 6.6 & $* * *$ & \\
\hline 19- AQ, Supporter, clear majority & 42.7 & 3.5 & $* * *$ & \multirow{2}{*}{ ns } \\
\hline 20- PQ, Supporter, clear majority & 41.6 & 2.8 & $* * *$ & \\
\hline Round number & 1.115 & 0.33 & & \\
\hline Round number to the square & -0.040 & 0.017 & & \\
\hline Round number to the cube & 0.0004 & 0.0002 & & \\
\hline R-squared & 0.19 & & & \\
\hline Total observations & 6911 & & & \\
\hline
\end{tabular}

$* * *, * *, *=$ null rejected at $1 \%, 5 \%$ and $10 \% ; \mathrm{ns}=$ null not rejected at $10 \%$.

$\mathrm{NQ}=$ No Quorum, AQ = Approval Quorum, $\mathrm{PQ}=$ Participation Quorum

In the No Quorum treatment the game is totally symmetric and, therefore, there are no distinctions between Opponents and Supporters.

Second to the last column: Wald test for the null that the Approval or Participation Quorum treatment has no effect when compared to the No Quorum treatment

Last column: Wald test for the null that the Participation Quorum treatment has no effect when compared to the Approval Quorum treatment 


\subsection{Quorum-busting strategies}

Discussing the effects of quorum rules, particularly in what concerns referenda and initiatives, leads us to discussing the possibility of boycotts, i.e. electors who decide to abstain with the firm objective of helping the quorum not to be met. Such outcome has been described in historical reports of full-fledged boycotts of direct democracy initiatives on the part of defenders of the Status Quo under participation quora, as in Italy (Uleri 2002; Kaufmann et al. 2008), Weimar Germany (West 1985; Suksi 2002), and several others (International IDEA 2008).

In our setup, that basically corresponds to choosing a willingness to pay equal to zero. To describe the impact of the quorum restrictions on the probability of boycotting an election in our experimental setup, we created a dummy variable, call it Boycott, that takes the value one if $\mathrm{WTP}=0$ and zero otherwise. Then, we estimate a binary choice model, with the help of a random effects probit model. We also included a quadratic time trend, i.e., the round number. ${ }^{23}$

Table 6 shows our results and Figure 3 provides a graphical illustration of the most significant findings. In the first two columns of the table, we have the typical information: information on the estimated coefficients and standard errors for the different treatments. In the third column, we convert that information into the probability of boycotting and, in the last two columns, we show the marginal effects. By marginal effects we mean the impact on the probability of boycotting an election from changing from "no quorum treatment" to a "quorum treatment" (in the second to the last column), and on the probability of boycotting an election from changing an “approval quorum treatment" to a "participation quorum treatment" (last column). ${ }^{24}$

While neither quorum significantly impacts the probability that a Supporter boycotts, both quora make it significantly more likely that an Opponent does so. For every treatment, the likelihood of Opponents boycotting an election increases significantly.

The approval quorum raises this probability by a value between 14 and 24 percentage points. With one exception, the differences in the impacts of the different quorum rules are statistically significant at $1 \%$. The exception is when an Opponent expects to be in clear minority. In that case, the marginal effect is significant at $5 \%$.

\footnotetext{
${ }^{23}$ The third order polynomial was statistically non-significant

${ }^{24}$ To compute the probability of boycott and the marginal effects, we considered Round number $=25$.
} 


\section{Table 5: Random effects Probit on Boycotting elections}

\begin{tabular}{|c|c|c|c|c|c|}
\hline & Coefficient & Std. Error & $\begin{array}{l}\text { Probability } \\
\text { of Boycott }\end{array}$ & $\begin{array}{c}\text { Marginal } \\
\text { effects } \\
\text { Q-NQ }\end{array}$ & $\begin{array}{c}\text { Marginal } \\
\text { effects } \\
\text { PQ-AQ }\end{array}$ \\
\hline 1- Constant & -1.05 & 0.19 & 26.0 & & \\
\hline 2- AQ, Opponent, clear minority & 0.38 & 0.20 & 39.7 & $13.8 * *$ & \multirow{2}{*}{$37.8 * * *$} \\
\hline 3- PQ, Opponent, clear minority & 1.40 & 0.26 & 77.6 & $51.6^{* * *}$ & \\
\hline 4- AQ, Supporter, clear minority & -0.15 & 0.14 & 21.2 & -4.7 & \multirow{2}{*}{-1.1} \\
\hline 5- PQ, Supporter, clear minority & -0.19 & 0.19 & 20.2 & -5.8 & \\
\hline 6- No Quorum, borderline minority & -0.93 & 0.16 & 5.8 & & \\
\hline 7- AQ, Opponent, borderline minority & 0.01 & 0.21 & 26.1 & $20.3^{* * *}$ & \multirow{2}{*}{$41.9 * * *$} \\
\hline 8- PQ, Opponent, borderline minority & 1.11 & 0.26 & 68.0 & $62.2^{* * *}$ & \\
\hline 9- AQ, Supporter, borderline minority & -0.91 & 0.15 & 6.0 & 0.2 & \multirow{2}{*}{0.3} \\
\hline 10- PQ, Supporter, borderline minority & -0.89 & 0.17 & 6.2 & 0.4 & \\
\hline 11- No Quorum, borderline majority & -1.68 & 0.31 & 1.0 & & \\
\hline $\begin{array}{l}\text { 12- AQ, Opponent, borderline } \\
\text { majority }\end{array}$ & -0.05 & 0.17 & 24.2 & $23.2 * * *$ & \multirow{2}{*}{$33.1 * * *$} \\
\hline 13- PQ, Opponent, borderline majority & 0.83 & 0.31 & 57.4 & $56.4 * * *$ & \\
\hline $\begin{array}{l}\text { 14- AQ, Supporter, borderline } \\
\text { majority }\end{array}$ & -1.42 & 0.21 & 1.9 & 0.9 & \multirow{2}{*}{0.8} \\
\hline 15- PQ, Supporter, borderline majority & -1.28 & 0.27 & 2.7 & 1.7 & \\
\hline 16- No Quorum, clear majority & -1.22 & 0.21 & 3.1 & & \\
\hline 17- AQ, Opponent, clear majority & 0.04 & 0.14 & 27.2 & $24.1 * * *$ & \multirow{2}{*}{$28.7 * * *$} \\
\hline 18- PQ, Opponent, clear majority & 0.79 & 0.27 & 55.9 & $52.8^{* * *}$ & \\
\hline 19- AQ, Supporter, clear majority & -1.44 & 0.20 & 1.9 & $-1.2 *$ & \multirow{2}{*}{-0.5} \\
\hline 20- PQ, Supporter, clear majority & -1.55 & 0.20 & 1.4 & -1.7 & \\
\hline Round number & 0.022 & 0.007 & & & \\
\hline Round number to square & -0.0002 & 0.0001 & & & \\
\hline Total observations & & 6911 & & & \\
\hline
\end{tabular}

$* * *, * *, *=$ null rejected at $1 \%, 5 \%$ and $10 \%$

$\mathrm{NQ}=$ No Quorum, $\mathrm{AQ}=$ Approval Quorum, $\mathrm{PQ}=$ Participation Quorum

In the No Quorum treatment the game is totally symmetric and, therefore, there are no distinctions between Opponents and Supporters. 


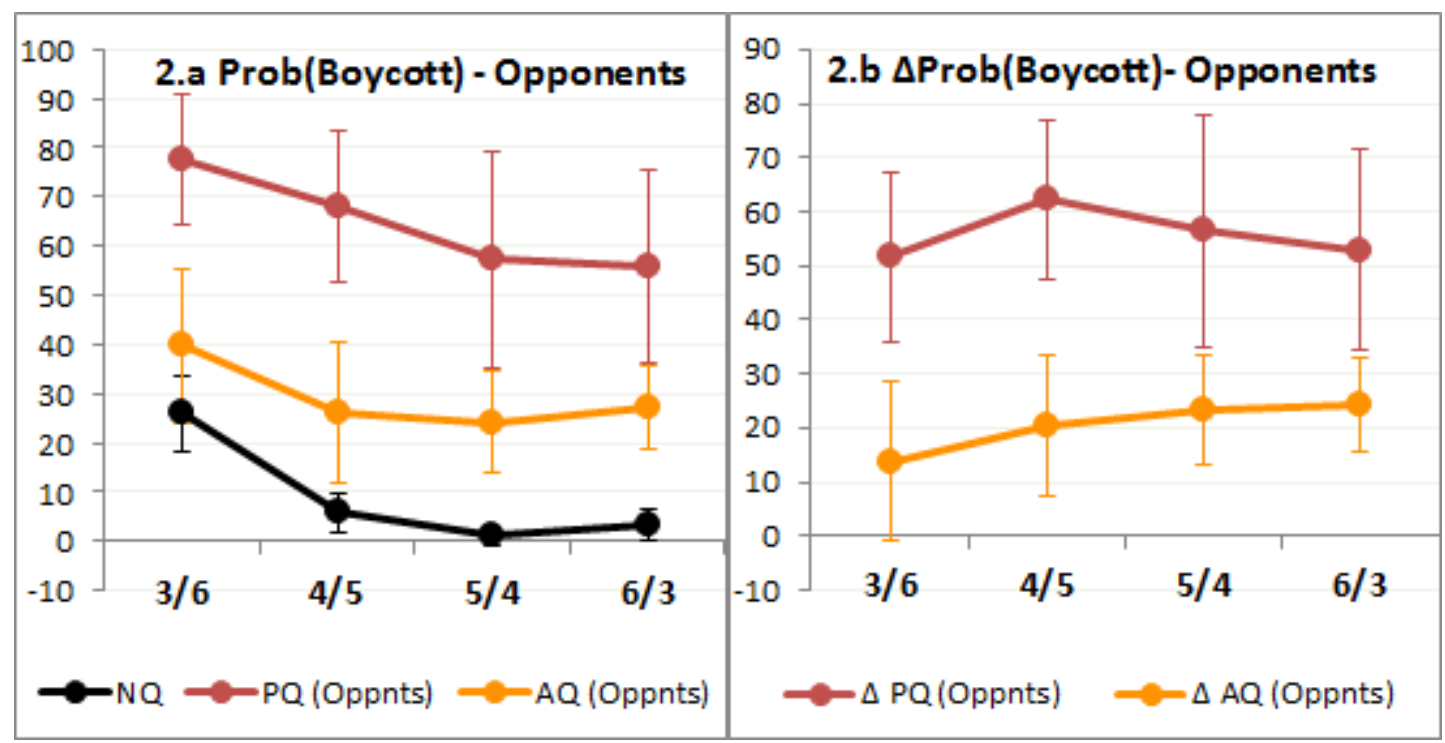

Figure 1: Experimental results. (a) The probability that an elector boycotts the election without quorum (NQ) and, for Opponents, the participation quorum (PQ) and the participation quorum (AQ). (b) The marginal effects of quora for Opponents in comparison with the no quorum situation. Error bars denote $95 \%$ confidence intervals.

The impact of the participation quorum is dramatically stronger: the increase is at least of 51 percentage points and can reach 62 points. The marginal effect on the probability that an Opponent boycotts an election is always significant at $1 \%$, both when compared with the no quorum and with the approval quorum treatments. Note also that, for this case, when one compares the participation quorum with the approval quorum, the stronger impact of the participation quorum is always significant at $1 \%$.

Result 4: Both $P Q$ and $A Q$ significantly increase the likelihood of complete abstention ("boycot") on the part of Opponents. The likelihood of boycott is significantly larger under $P Q$ than $A Q$ 


\section{Conclusions}

Studies of the determinants of turnout in direct democracy settings are rare, tend to focus on determinants such as the closeness of the election or the consequences of ballot issues, and have relied mostly on observational data (Filer and Kenny 1980; Matsusaka 1993; Coate and Conlin 2004; Coate et al. 2008). In this paper, motivated by a widespread aspect of direct democracy design - the adoption of quorum rules we examine its consequences on turnout using a laboratory experiment.

We found that the main prediction of the pivotal voter model, extended to accommodate quorum rules, was confirmed: participation rates of Opponents were lower in the presence of quora. However, two additional findings emerge. First, we found evidence that participation quora produce a strongest demobilization effect among those who oppose changing the Status Quo than do approval quora. While the participation quorum increased the probability of Opponents boycotting the election by 50 to 60 percentage points, the same sort of effect was not nearly as dramatic for approval quorum treatment. Finally, we found that the demobilization effect of quora takes place only among Opponents of change, not among Supporters. In fact, in some situations, the turnout among Supporters of measures changing the Status Quo is slightly increased.

As with virtually all research using laboratory experiments, it is important to consider the external validity of our results. Two differences between the laboratory setting and potential "real world" applications are prominent. First, the laboratory game is arguably much simpler than any real world situation. For example, participants in our experiments are perfectly informed about the payoffs they will receive depending on the outcome of the vote, and there is common knowledge about the expected number of supporters and opponents. While this is true, our design does involve two layers of uncertainty. There is uncertainty about the voting costs and uncertainty about aggregate preferences. Thus, although our game is not nearly as complex as a real world election, it does capture at least some of the complexity faced by voters in real world settings.

A second difference between our experiment and potential real world settings is the relatively small number of participants. Our elections involve 9 players, while real world referenda are likely to involve many thousands. Therefore, the probability of 
casting a pivotal vote (either to affect a tie or to reach a quorum) is essentially zero in real world settings. Despite this important objection, many empirical studies have shown that patterns in voting behavior are in several respects generally consistent with the pivotal voter model. Thus it seems that many voters behave "as if" the number of voters is small. One set of advanced explanations is related to cognitive biases leading voters to overestimate small probabilities (Kahneman and Tversky 1979), whose effects can be amplified by attitudinal predispositions like, for example, their sense of political efficacy (Blais and Rheault 2011) or their level of risk aversion (St-Vincent 2013). Another possible explanation for this is that voters coordinate and / or respond to the (costly) mobilizing efforts of a relatively small number of "elite" leaders (Cox and Munger 1989; Matsusaka 1993). But from both perspectives, even with small numbers, the results of our experiment may provide valuable evidence as to the effects of quorum rules in situations involving a large number of participants. Future experiments should test the robustness of our results to a number of different extensions. One such extension could allow for communication among subjects, while keeping voting anonymous. This way, they may coordinate strategies to select a particular equilibrium. Another potentially interesting experiment will be to allow for negative voting costs, to capture the possibility of expressive voting and the idea of voting by civic duty. According to Aguiar-Conraria and Magalhães (2010b) this extension may help differentiate the approval from the participation quorum even further. Finally, allowing for different intensity in preferences to test the effect of quora on the behavior of active minorities may also lead to relevant results.

On the basis of this experiment, however, the results already point to several potential awkward consequences of quora. Designed to protect the Status Quo, they seem not only to depress Opponents' participation but also to stimulate the participation of Supporters. In other words, when quora are nevertheless met, they end up having favored Change. If, in turn, Opponents engage in boycotts that happen to be successful, huge majorities of expressed preferences in favor of Change will nevertheless fail to pass it. Furthermore, in real world conditions, full boycotts on the part of Opponents, which we showed to be massively increased by participation quora, make the preferences of those who vote (Supporters) common knowledge, endangering the secrecy of the vote. Finally, quora decrease overall levels of turnout, potentially affecting, in real world conditions, the perceived "legitimacy" of results. 


\section{References}

Aguiar-Conraria, L., \& Magalhães, P. C. (2010a). Referendum design, quorum rules and turnout. Public Choice, 144(1), 63-81.

Aguiar-Conraria, L., \& Magalhães, P. C. (2010b). How quorum rules distort referendum outcomes: Evidence from a pivotal voter model. European Journal of Political Economy, 26(4), 541-557.

Allen Jr, J. L. (2005), Cardinal Ruini's Victory: Low Voter Turnout for In Vitro Referendum is Ascribed to Church's Political Muscle in Italy. National Catholic Reporter, July 1st.

Altman, D. (2011). Direct Democracy Worldwide. Cambridge Univ. Press

Battaglini, M., Morton, R. B., \& Palfrey, T. R. (2010). The swing voter's curse in the laboratory. The Review of Economic Studies, 77(1), 61-89.

Blais, A. (2000). To vote or not to vote? Pittsburgh: Univ of Pittsburgh Press.

Blais. A., \& Rheault, L. (2011). Optimists and skeptics: Why do people believe in the value of their single vote? Electoral Studies, 30, 77-82.

Börgers, T., (2004). Costly voting. American Economic Review 94(1), 57-66.

Brandts, J., \& Charness, G. (2011). The strategy versus the direct-response method: a first survey of experimental comparisons. Experimental Economics, 14(3), 375-398.

Coate, S., Conlin, M. \& Moro, A. (2008). The performance of pivotal-voter models in small-scale elections: evidence from Texas liquor referenda. Journal of Public Economics 92(3-4), 582-596.

Coate, S. \& Conlin, M. 2004. A group rule-utilitarian approach to voter turnout: theory and evidence. American Economic Review 94 (5), 1476-1504.

Côrte-Real, P., Pereira, P.T. (2004). The voter who wasn't there: referenda, representation and abstention. Social Choice and Welfare 22(2), 349-369.

Cox, G. W., \& Munger, M. C. (1989). Closeness, Expenditures, and Turnout in the 1982 US House Elections. American Political Science Review, 83(01), 217-231.

Dhillon, A. \& Peralta, S.. 2002. Economic Theories of Voter Turnout. The Economic Journal 112, 332-352.

Duffy, J., Tavits, M. (2008). Beliefs and voting decisions: A test of the pivotal voter model. American Journal of Political Science, 52 (3), 603-618.

Eder, C., Vatter, A. \& Freitag, M. (2009). Institutional design and the use of direct democracy: Evidence from the German Länder. West European Politics, 32 (3), 611633.

Fedderson, T. (2004). Rational Choice Theory and the Paradox of Not Voting. Journal of Economic Perspectives, 18, 99-112.

Filer, J. E., \& Kenny, L. W. (1980). Voter turnout and the benefits of voting. Public Choice, 35(5), 575-585.

Fischbacher, U. (2007). z-Tree: Zurich Toolbox for Ready-Made Economic Experiments. Experimental Economics, 10, 171-178.

Fréchette, G. (2012). Session-effects in the laboratory. Experimental Economics, 15, 485498.

Geys, B. (2006). Explaining voter turnout: A review of aggregate-level research. Electoral Studies, 25, 637-663.

Großer, J., \& Schram, A. (2006). Neighborhood information exchange and voter participation: an experimental study. American Political Science Review, 100(2), 235-248.

Großer, J., \& Schram, A. (2010). Public opinion polls, voter turnout, and welfare: An experimental study. American Journal of Political Science, 54(3), 700-717. 
Greiner, B. (2004). An Online Recruitment System for Economic Experiments. In Forschung und Wissenschaftliches Rechnen 2003, ed. By K.Kremer and V.Macho.

GWDG Bericht 63. Gesellschaft für Wissenschaftliche Datenverarbeitung Göttingen : Datenverarbeitung, 79-93.

Herrera, H., Mattozzi, A. (2010). Quorum and turnout in referenda. Journal of the European Economic Association 8(4), 838-871.

Hizen, Y., \& Shinmyo, M. (2011). Imposing a turnout threshold in referendums. Public Choice, 148(3), 491-503.

Hug, S. (2004). Occurrence and policy consequences of referendums. A theoretical model and empirical evidence. Journal of Theoretical Politics, 16(3), 321-356.

Hug, S., \& Tsebelis, G. (2002). Veto players and referendums around the world. Journal of Theoretical Politics, 14(4), 465-515.

International IDEA, 2008. Direct Democracy: The International IDEA Handbook. International Institute for Democracy and Electoral Assistance, Stockholm.

Kahneman, D., \& Tversky, A. (1979). Prospect theory: An Analysis of of decision under risk. Econometrica, 47, 263-292.

Kaufmann, B., Büchi, R., \& Braun, N. (2008). Guidebook to Direct Democracy in Switzerland and Beyond. Initiative \& Referendum Institute Europe. Marburg.

Kittel, B., and Marcinkiewicz, K. (2012). Voting Behavior and Political Institutions: An Overview of Challenging Questions in Theory and Experimental Research. In B. Kittel, W. J. Luhan, and R. Morton (Eds.), Experimental Political Science: Principles and Practices. Houndmills: Palgrave MacMillan.

Laruelle, A., \& Valenciano, F. (2012). Majorities with a quorum. Journal of Theoretical Politics, 23(2), 241-259.

Laruelle, A., \& Valenciano, F. (2012). Quaternary dichotomous voting rules. Social Choice and Welfare, 38(3), 431-454

LeDuc, Lawrence. 2003. The Politics of Direct Democracy: Referendums in Global Perspective. Toronto: Broadview Press.

Levine, D. K., \& Palfrey, T. R. (2007). The paradox of voter participation? A laboratory study. American Political Science Review, 101(1), 143-158.

Matsusaka, J. G. (1993). Election closeness and voter turnout: Evidence from California ballot propositions. Public Choice, 76(4), 313-334.

Matsusaka, J.G., 2005. Direct democracy works. The Journal of Economic Perspectives, 19, 185-206.

Morton, R. B., \& Tyran, J. R. (2011). Let the experts decide? Asymmetric information, abstention, and coordination in standing committees. Games and Economic Behavior, 72(2), 485-509.

Morton, R. B. \& Williams, K. C. (2010) Experimental Political Science and the Study of Causality, Cambridge Univ. Press, New York.

Myerson, R. B. (2000). Large poisson games. Journal of Economic Theory, 94(1), 7-45.

Palfrey, T. R. (2009). Laboratory experiments in political economy. Annual Review of Political Science, 12, 379-388.

Palfrey, T. \& Rosenthal, H. (1985). Voter participation and strategic uncertainty. American Political Science Review, 79(1): 62-78.

Papke, L. \& Wooldridge, J. (2008). Panel data methods for fractional response variables with an application to test pass rates. Journal of Econometrics 145: 121-133.

Qvortrup, M. (2005). A Comparative Study of Referendums. Manchester University Press, Manchester UK.

Schiller, T. (2011). Local Direct Democracy in Europe. Wiesbaden: VS Verlag.

Schram, A., \& Sonnemans, J. (1996). Voter turnout as a participation game: an 
experimental investigation. International Journal of Game Theory, 25(3), 385-406.

St-Vincent, S. L. (2013). An experimental test of the pivotal voter model under plurality and PR elections. Electoral Studies, 32, 795-806.

Suksi, M. (1993). Bringing in the People: A Comparison of the Constitutional forms and Practices of the Referendum. Martinus Nijhoff Publishers, Dordrecht.

Svensson, P. (1996). Denmark: the referendum as minority protection. In Uleri, P. V.

(Ed.), The referendum experience in Europe. Basignstoke: Macmillan.

Uleri, P.V. (2002). On referendum voting in Italy: yes, no or non-vote? How Italian parties learned to control referendums. European Journal of Political Research 41(6), 863883.

Venice Commission. (2007). Code of good practice on referendums. Document CDL$A D(2007) 008$. Available at http://www.venice.coe.int/docs/2007/CDL$\mathrm{AD}(2007) 008$-e.asp.

Verhulst, J. \& A. Nijeboer. (2008). Direct Democracy: Facts and Arguments about the Introduction of Initiative and Referendum. Brussels: Democracy International.

West, F.C. (1985). A Crisis of the Weimar Republic: A Study of the German Referendum of 20 June 1926. American Philosophical Society, Philadelphia PA. 


\section{Appendix 1 - The mathematics of the pivotal voter model with quorum requirements}

Assume that if 'Yes' wins the election, Supporters obtain a benefit $b$. Opponents have a benefit of $x$. Assume also that there are 9 electors $(i=1, \ldots, 9)$ and that each faces a cost of voting given by $c_{i}$, where $c_{i}$ is the realization of a uniformly distributed random variable, $c_{i} \sim U[0,100]$. Each voter knows her own cost, but only knows the cost distribution of the other voters. Also, each elector knows her own type and knows the probability that each other individual elector favors the proposal. A strategy is a function that specifies if elector $i$ votes or abstains for each possible realization of $c_{i}$. A symmetric Bayesian-Nash equilibrium implies that all members of a group follow the same strategy. An elector will vote if the voting cost is below some threshold. Let $\gamma_{s}$ and $\gamma_{o}$ be those cutoff values for supporters of Change and Opponents, respectively. Taking as given the strategies of the other players, let $\rho\left(v_{o}, v_{s}\right)$ be the probability that elector $i$ attaches that, among the other electors, $v_{o}$ vote 'No' and $v_{s}$ vote 'Yes'. 25

To derive $\rho\left(v_{o}, v_{s}\right)$, note that the probability that there are $s$ supporters among the remaining $n-1$ electors is given by $P(s ; i)=\left(\begin{array}{c}n-1 \\ s\end{array}\right) \mu^{s}(1-\mu)^{n-1-s}$. Among the $s$ supporters, only the ones whose individual costs are smaller than their cutoff value will vote. Therefore, the probability that $v_{s}$ of those will vote is $V\left(v_{s}\right)=$ $\left(\begin{array}{c}s \\ v_{S}\end{array}\right)\left(\frac{\gamma_{s}}{c}\right)^{v_{s}}\left(1-\frac{\gamma_{s}}{c}\right)^{s-v_{S}}$. Similarly the probability that, among the other $n-1-s$ electors, $v_{o}$ will vote 'No' is $V\left(v_{o}\right)=\left(\begin{array}{c}n-1-s \\ v_{o}\end{array}\right)\left(\frac{\gamma_{o}}{c}\right)^{v_{o}}\left(1-\frac{\gamma_{o}}{c}\right)^{n-1-s-v_{o}}$. Putting all these together, we have:

$$
\begin{aligned}
\rho\left(v_{s}, v_{o}\right)= & \sum_{s=v_{s}}^{n-1-v_{o}}\left(\begin{array}{c}
s \\
v_{s}
\end{array}\right)\left(\frac{\gamma_{s}}{c}\right)^{v_{s}}\left(1-\frac{\gamma_{s}}{c}\right)^{s-v_{s}}\left(\begin{array}{c}
n-1-s \\
v_{o}
\end{array}\right)\left(\frac{\gamma_{o}}{c}\right)^{v_{o}}(1 \\
& \left.-\frac{\gamma_{o}}{c}\right)^{n-1-s-v_{o}}\left(\begin{array}{c}
n-1 \\
s
\end{array}\right) \mu^{s}(1-\mu)^{n-1-s} .
\end{aligned}
$$

\footnotetext{
${ }^{25}$ This is an obvious abuse of notation, as $\rho($.) depends on the strategies of the other players, which also depend on the existing quorum requirement. We refer the reader to Aguiar-Conraria and Magalhães (2010b) for a rigorous derivation of the model.
} 
Consider the case of no quorum; a Supporter is pivotal if her vote is necessary either to break or to reach the tie. So the probability of being pivotal is given by $\left[\sum_{v=0}^{4} \frac{\rho(v, v)}{2}+\sum_{v=0}^{3} \frac{\rho(v+1, v)}{2}\right]$. For a Opponent the probability is given by $\sum_{v=0}^{4} \frac{\rho(v, v)}{2}+$ $\sum_{v=0}^{3} \frac{\rho(v, v+1)}{2}$.

Next, consider the participation quorum of 4 . This rule introduces an additional way in which a voter may be pivotal. Namely, it could be that her vote is decisive in reaching the quorum, in addition to reaching or breaking a tie in case the quorum is met. For an Opponent, this means that she may be pivotal in an undesirable way: if her vote is decisive to meet the quorum and a majority votes in support of change, then her vote actually causes "Change" to win.

Finally, consider the approval quorum of 3. A Supporter may be pivotal either to guarantee, or break, the tie or to reach the quorum. In contrast, an Opponent has no influence in the quorum in this case, so she can only be pivotal to guarantee or break the tie, assuming that the quorum is reached. Thus, the AQ rule effectively eliminates the possibility to be pivotal in an undesirable way.

Putting all this together, for an Supporter, the expected benefit of voting and the equilibrium conditions are given by:

$$
\left\{\begin{array}{l}
{\left[\sum_{v=0}^{4} \frac{\rho(v, v)}{2}+\sum_{v=0}^{3} \frac{\rho(v+1, v)}{2}\right] b=\gamma_{s^{\prime}}, \text { if } N Q} \\
{\left[\sum_{v=2}^{4} \frac{\rho(v, v)}{2}+\sum_{v=1}^{3} \frac{\rho(v+1, v)}{2}+\rho(1,2)+\rho(0,3)\right] b=\gamma_{s^{\prime}}, \text { if } P Q=4} \\
{\left[\sum_{v=3}^{4} \frac{\rho(v, v)}{2}+\sum_{v=2}^{3} \frac{\rho(v+1, v)}{2}+\sum_{v=0}^{2} \rho(v, 2)\right] b=\gamma_{s^{\prime}} \quad \text { if } A Q=3}
\end{array}\right.
$$

For an Opponent, the expected benefit of voting and the equilibrium conditions are given by:

$$
\left\{\begin{array}{l}
{\left[\sum_{v=0}^{4} \frac{\rho(v, v)}{2}+\sum_{v=0}^{3} \frac{\rho(v, v+1)}{2}\right] x=\gamma_{o}, \quad \text { if } N Q} \\
{\left[\sum_{v=2}^{4} \frac{\rho(v, v)}{2}+\sum_{v=2}^{3} \frac{\rho(v+1, v)}{2}-\frac{\rho(1,2)}{2}-\rho(0,3)\right] x=\gamma_{o}, \quad \text { if } P Q=4} \\
{\left[\sum_{v=3}^{4} \frac{\rho(v, v)}{2}+\sum_{v=2}^{3} \frac{\rho(v, v+1)}{2}\right] x=\gamma_{o}, \quad \text { if } A Q=3}
\end{array}\right.
$$


Note that in the participation quorum case, an Opponent may be pivotal in an undesirable way if her vote is decisive to meet the quorum, hence the negative signs in the second equation.

For each quorum treatment, we have two equations and two unknowns. We find the equilibria numerically. Existence of solutions is not a problem, but there are no general uniqueness results. However, given that our problem is only two-dimensional and bounded, one can perform a detailed grid search to look for several equilibria. Only in the case of no quorum, we found unique equilibria. 


\section{Appendix 2 - Experiment instructions}

\section{The following instructions were displayed (in German) on screen when subjects entered the laboratory:}

\section{Instructions}

Thank you for participating in this experiment. Please read the following instructions carefully. If you have a question, silently raise your hand.

\section{General Rules}

- This experiment will last for approximately 90 minutes. During this time, you should not leave your place.

- Please turn off and put away your mobile phone. Starting now, there should be nothing on your table. (A drink is permitted.)

- Please remain quiet during the experiment, and do not speak to other participants.

- At the end of the experiment, stay at your sear until your number is called. You will then be paid and you will sign a receipt.

- You will receive further instructions after all participants have taken their seats."

After all subjects had taken their seats, an announcement was made that instructions for the experiment would be displayed. Subjects were told that the instructions cover six screens and that they would be able to navigate back and forth as often as they wished. The following screens were then displayed in sequence, with "forward" and "back" buttons displayed at the bottom of the screen.

\section{Screen 1}

\section{Rounds, Points, Payment}

- You will receive a 5 EUR participation fee for participating. During the experiment, you may attain either a higher or lower payment.

- Your payment will depend on your decisions and those of other participants.

- The experiment consists of 48 rounds, each of which is independent of the others. In every round, you will have the opportunity to earn points. At the end of the experiment, 10 rounds will be randomly chosen for payment.

- Your payment will depend on your average number of points in the randomly chosen rounds. Points are exchanged for payment at the ratio

$$
1 \text { point }=0.05 \text { EUR }
$$

- If you should earn a negative number of points during the experiment, the corresponding amount will be subtracted from your show-up fee. However, your payment will be positive in all cases.

\section{Screen 2}

\section{What happens during a round?}

- At the start of each round, every participant draws a ball from a (virtual) urn. The ball is marked either "A" or " $B$ ". (Additional details regarding the composition of the urn will follow below.)

- After this, you and 8 other participants (i.e. a group of 9 participants) will make a choice. 
- The members of the group choose between two options " $\mathrm{A}$ " and "B" by way of voting. (Details regarding the voting rules will follow below.)

- If the option chosen by your group ("A" or "B") matches the ball you have drawn ("A" of "B"), you will receive 600 points in this round.

$($ Remember: 1 point $=0.05$ EUR. Thus 600 points $=30$ EUR $)$

\section{Screen 3}

\section{Details: Urn and Balls}

- Every participant draws a ball from his or her own urn, independently of other participants.

- The urn contains 9 balls. Some are marked "A", the others are marked "B". The composition of the urn will vary from one round to the next.

- You will be informed about the number of balls marked "A" and "B" at the beginning of each round.

- Within a given round, the number of balls " $\mathrm{A}$ " and " $\mathrm{B}$ " are the same for all participants. The chances of drawing a ball marked "A" or a ball marked "B" are therefore the same for all participants.

Example: Suppose that the urn contains 4 balls marked "A" and 5 balls marked "B".

- In this example, the probability that you will draw a ball marked "A" is $4 / 9$. The probability that you will draw a ball marked " $\mathrm{B}$ " is $5 / 9$. The same is true for all other participants.

- In this example, it will not necessarily be the case that 4 participants will draw a ball marked "A" and 5 participants will draw a ball marked "B". For example, it is possible (though unlikely) that all participants will draw a ball marked "A".

\section{Screen 4}

\section{Details: Voting}

- In each round, every participant will decide whether he wishes to vote or whether he wishes not to vote.

- If the participant chooses to vote, a certain number of points will be subtracted from his total in that round. We will refer to the number of points subtracted as his voting cost.

- Your voting costs lie between $\mathbf{0}$ and $\mathbf{1 0 0}$ points. They will be randomly determined for each participant at the beginning of every round. Every number between 0 and 100 points is equally likely. (Remember: 1 point $=0.05$ EUR. Therefore 100 points $=5$ EUR.)

- Every participant is assigned his own voting cost in each round. In general, these costs will therefore differ between participants.

- If a participant decides to vote, then a vote for the option corresponding to his ball is automatically counted.

Example: Suppose you draw a ball marked "A". If you choose to vote, then one vote for option " $\mathrm{A}$ " is automatically counted.

\section{Screen 5}

\section{Details: Your Decision}

- In order to better understand your decision (vote or not vote), we will proceed as follows.

- In each round, we will ask you to state how much you are willing to pay, at most, in order to cast a vote in this round. 
- Important: We will ask this question before we inform you of your actual voting cost in the round. (However you will know the composition of the urn, the ball you have drawn, and the voting rule that is in effect.)

- If your voting cost is smaller than or equal to your stated willingness to pay, you will cast a vote and "pay" the voting cost (not your stated willingness to pay).

- If your voting cost is larger than your stated willingness to pay, you will not cast a vote.

- Your statement has no influence on your actual voting cost. This cost is randomly determined already before you make your decision.

\section{Screen 6}

\section{Details: Voting Rule}

- After all participants have decided (as described above) to vote or not to vote, the votes cast are counted.

- $\quad$ Recall that when a participant votes, a vote for the option corresponding to his ball is automatically counted.

- In principle: The option which receives the most votes is chosen. In case of a tie, a random choice is made (50/50).

- However: In addition, in some rounds, there will be a so-called quorum rule. This rule states that one of the two options (A or B) will be automatically chosen if fewer than 4 votes are cast [fewer than 3 votes are cast for the other option].

Example: Suppose the quorum rule states: "If fewer than 4 votes [3 votes for option B] are cast, option A will automatically win." Then if, for example, 2 votes for option B and one vote for option A are cast, option A will win despite that B has a majority of the votes.

- You will be informed prior to making your decision about whether a quorum rule is in effect, and which option will win if the quorum is not met.

- Note: If the option corresponding to your ball wins, you will receive 600 points, even if you have not cast a vote. 
Screenshot 1: drawing a ball

Runde: 1

URNE :

$\begin{array}{llll}\text { A A A } & \text { Kugeln A: } & 6 \\ \text { A A A } & \text { Kugeln B: } & 3 \\ \text { B } & \text { B } & & \end{array}$

IHRE KUGEL:

ziehen

Screenshot 2: Input willingness to pay

Runde: 1

URNE :

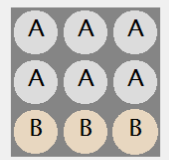

Kugeln A: $\quad 6$

Kugeln B:

3

IHRE KUGEL:

A

Wenn Option A gewinnt,

erhalten Sie 600 Punkte.

QUORUM-REGEL: Wenn weniger als 4 Stimmen

abgegeben werden, gewinnt automatisch

Option B

ENTSCHEIDUNG: Wieviel sind Sie maximal zu zahlen bereit,

um eine Stimme für A abzugeben?

Ihre Angabe (0-100): 
Screenshot 3: Feedback after cost draw

Runde: 1

URNE :

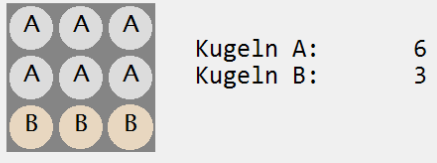

IHRE KUGEL:

A Wenn Option A gewinnt,
erhalten Sie 600 Punkte.

QUORUM-REGEL: Wenn weniger als 4 Stimmen

abgegeben werden, gewinnt automatisch

Option B

ENTSCHEIDUNG: Wieviel sind Sie maximal zu zahlen bereit,

um eine Stimme für $A$ abzugeben?

Ihre Angabe (0-100): Ihre Abstimmungskosten:

3253

Sie werden nicht abstimmen.

\section{OK}

Screenshot 4: Feedback at end of round

Runde: 1

URNE :

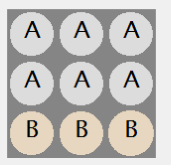

Kugeln A: $\quad 6$

Kugeln B: $\quad 3$

IHRE KUGEL:

B Wenn Option B gewinnt, erhalten Sie 600 Punkte.

QUORUM-REGEL: Wenn weniger als 4 stimmen

abgegeben werden, gewinnt automatisch

Option B

ENTSCHEIDUNG: Sie werden nicht abstimmen.

ERGEBNIS: Teilnehmer mit Kugel A: 6 Stimmen für Option A: 2

Teilnehmer mit Kugel B: $3 \quad$ Stimmen für Option B: 1

Das Quorum wurde nicht erfüllt.

Es gewinnt: Option B (Quorum verfehlt)

IHRE PUNKTE: 600 (Ergebnis Abstimmung) $-\theta$ (Abstimmungskosten) $=600$

\section{OK}

